\title{
A ANÁLISE DO MODELO DE MEDIAÇÃO E CONCILIAÇÃO PROPOSTO PELO CPC/2015 À LUZ DO CONCEITO DE CONFLITOS COMO PROPRIEDADE
}

\author{
ANALYSIS OF THE MEDIATION AND ‘CONCILIATION’ SYSTEM BROUGHT BY THE 2015 CIVIL \\ PROCEDURE CODE IN THE LIGHT OF THE CONCEPT OF CONFLICTS AS PROPERTY
}

\section{Rafael Machado Viviani Nicolau*}

\begin{abstract}
Resumo:
O presente artigo analisa de maneira crítica os mecanismos de mediação e conciliação no Código de Processo de 2015 com base nas ideias de Nils Christie em Conflicts as Property. De forma geral, destacam-se alguns pontos positivos trazidos pelo Novo CPC, bem como outros negativos, e contextualiza-se o CPC de 2015 dentro do Movimento ADR. Conclui-se pela enorme responsabilidade das Universidades, que devem buscar um ensino jurídico adequado às reais necessidades da sociedade, formando profissionais questionadores e produtores de conhecimento, que promovam a cultura da pacificação, da restauração e da inclusão da sociedade leiga nos processos de resolução de conflitos.

Palavras-chave: Mediação. Conciliação. CPC 2015. Conflitos. ADR. Justiça Restaurativa. Apropriação. Pacificação.

Abstract:

The present essay analyses, with a critical view, the institutes of mediation and conciliation in the 2015 Brazilian Civil Procedure Code, based on Nils Christie's ideas in Conflicts as Property. Both positive and negative aspects of the New Code are brought to light, inserting the 2015 CPC into the context of the ADR Movement. The conclusion is Universities should pursue to adjust their teachings of Law to the real needs of the community, forming professionals who question and create knowledge, promoting the amicable conflict-solving culture ("Pacification Culture"), restorative Justice, and the inclusion of the lay community in the processes of conflict solving.
\end{abstract}

Keywords: Mediation. Conciliation. 2015 CPC. ADR. Restorative Justice. Appropriation. Pacification.

\section{Introdução à pesquisa}

O Brasil, por meio do CPC de 2015, optou pela ampla utilização dos mecanismos de mediação e conciliação. O presente artigo procura discutir os motivos e consequências desta mudança legislativa, analisando o sistema de mediação e conciliação proposto pelo Código de Processo Civil de 2015 à luz do conceito de conflitos como

\footnotetext{
* Advogado. Formado em Direito pela Universidade de São Paulo. E-mail: rafaelmvnicolau@hotmail.com. 
propriedade, ou seja, por intermédio do estudo de como as partes acabam tendo a resolução de seus conflitos afastada pelos operadores do Direito e pelas regras que visam a solução de seus litígios. Essa apropriação foi estudada pelo autor Nils Christie, que questionava temas como o funcionamento da Justiça e as formas de resolução de conflitos.

Portanto, a presente pesquisa percorre o seguinte caminho: no segundo capítulo, se apresenta o artigo de Nils Christie, que trata do tema da apropriação de conflitos ("Conflicts as Property"), apontando suas principais ideias. No terceiro capítulo, se desenha o contexto em que o Código de Processo Civil de 2015 está inserido, com destaque para o Movimento ADR. Por fim, no quinto e último capítulo, discute-se as conclusões da pesquisa.

\section{2. "Conflicts as property" e a ideia de apropriação de conflitos}

Nils Christie (1928-2015) foi um sociólogo e criminólogo norueguês que estudou questões como o cárcere, o crime e a proibição das drogas. No ano de 1977, publicou o artigo Conflicts as Property no The British Journal of Criminology, Delinquency, and Deviant Social Behaviour, publicação britânica no ramo da criminologia.

Trata-se de artigo relevante para a realidade brasileira, visto que o sistema de Justiça nacional pode ser alvo da maioria das críticas feitas por Christie. O autor Rafael Diniz Pucci (2015), em seu artigo “Governança Ambiental e Sistema Financeiro Internacional: Significantes e Significados de Complexa Comunicação na Agenda Contemporânea", nota que a obra de Nils Christie inaugurou a tradição restaurativa, e que foi considerado o artigo de maior influência da década de 1970 pelo British Journal of Criminology.

Nils Christie apresenta a ideia de que, frequentemente, as partes acabam sendo afastadas da resolução de seus próprios conflitos, visto que o Estado e os operadores do Direito tendem a se apropriar das controvérsias alheias, tratando-as como se fossem uma propriedade. Diversas características, que variam desde a arquitetura dos prédios públicos até o tipo de linguagem utilizada no mundo jurídico, explicam como ocorre essa apropriação de conflitos. Ao final de seu texto, Christie propõe um modelo diferente de resolver conflitos, em oposição a todas as críticas feitas ao longo do seu artigo.

A principal crítica é a de que as partes são alienadas do processo de resolução de seus próprios problemas. Geralmente, esses processos de resolução são técnicos, tediosos, dominados pelos profissionais do Direito, enquanto a comunidade é afastada. Nils Christie também constata que a sociedade moderna é muito segmentada, o que dificulta a participação da comunidade nos processos de resolução de controvérsias. No final do artigo, o autor propõe um modelo de Tribunal "de vizinhança", voltado para as vítimas, para os leigos, e com objetivo de reparar, e não de punir. Trata-se, da 
Justiça Restaurativa, cujo enfoque é "identificar e tratar danos, necessidades e obrigações, visando curar e colocar as coisas da melhor forma possível”, na definição trazida por Zehr e Gohar (2002).

As críticas do artigo são aplicáveis, em sua maioria, à realidade brasileira. Aqui, também, há o afastamento da comunidade (processos tediosos e técnicos, abuso de linguagem incompreensível para leigos, prédios públicos imponentes e centralizados que mais afastam do que aproximam o cidadão, audiências que ocorrem em salas fechadas, nas quais apenas as partes, seus advogados e o juiz participam).

Também se aplica a ideia de que os profissionais do Direito se apropriam dos conflitos. $\mathrm{Na}$ área criminal, a vítima é igualmente esquecida e substituída pelo Estado. Mesmo nos conflitos cíveis, os advogados e juízes transformam a resolução do conflito em discussão técnica, em geral buscando apontar um culpado, que será responsabilizado financeiramente pelo conflito.

É aplicável também a crítica quanto à escassez de conflitos. Ainda que não seja possível afirmar que os litígios no Brasil sejam raros, o número de advogados é tão desproporcionalmente grande no país que os conflitos passam a ser bens valiosos, passíveis de disputa como se propriedade fossem, entre os advogados.

Talvez as críticas do artigo quanto à ausência de vizinhanças se aplique de forma limitada ao Brasil. Por um lado, os grandes centros industrializados e urbanos perderam, de fato, o senso de comunidade. Por outro, ao olhar as comunidades mais pobres ou periféricas do país, constata-se a existência de um forte senso de vizinhança e união, não sendo incomum, inclusive, chamar regiões caracterizadas pela favelização pela denominação "comunidade", por exemplo, indicando um laço que une seus moradores. Ou seja, talvez existam melhores condições para a implantação do modelo proposto por Nils Christie no Brasil, do que em países desenvolvidos e industrializados, com vizinhanças menos delineadas.

Constata-se que também no Brasil existe reduzido número de conflitos puramente individuais (em face da proliferação de conflitos envolvendo empresas, corporações, bancos, planos de saúde), o que adiciona complexidade às discussões envolvendo métodos consensuais, em face das assimetrias e vulnerabilidades presentes nestes conflitos.

Por fim, vale dizer que grande parte das faculdades brasileiras tem por enfoque o litígio, o aspecto contencioso dos conflitos, bem como a formação de operadores do Direito. Assim, visam formar profissionais técnicos, especializados em litigar, em "vencer", em judicializar conflitos. Trata-se, infelizmente, do oposto do modelo descrito por Nils Christie, que aponta as universidades como as responsáveis por incitar o questionamento dos modelos estabelecido e o diálogo na resolução de conflitos. 
3. O Brasil inserido em tendências supranacionais

De forma breve, é importante notar que o Novo Código de Processo Civil de 2015, marcado pela valorização das técnicas consensuais de resolução de conflitos, se alinha a um movimento maior, de dimensões supranacionais, denominado "Movimento ADR". O “Alternative Dispute Resolution Movement” teve suas primeiras manifestações na década de 70, nos Estados Unidos da América, e nas décadas seguintes, foi conquistando espaço no cenário legislativo dos EUA. O "Alternative Dispute Resolution Act" (EUA, 1998) definiu procedimentos "ADR" como "um processo alternativo de resolução de disputas que inclui todo processo ou procedimento, distinto daquele em que há julgamento perante um juiz-presidente, em que uma terceira parte neutra participa para auxiliar na resolução de questões controversas".

Além do CPC de 2015, algumas outras medidas legislativas demonstram este movimento do Brasil rumo à adoção ampla dos métodos trazidos pelo Movimento ADR, como, por exemplo, o relatório do Ministério da Fazenda de 2004 denominado "Reformas Microeconômicas e Crescimento a Longo Prazo" (que pregava a utilização da mediação), a Lei de Mediação de 2015 e a Resolução n. 125 do CNJ.

Há que se constatar, em aspecto mais amplo, que a necessidade de promulgar novas regras processuais no Brasil também se insere em um contexto de tendências de uma "nova arquitetura do Direito", apontadas pelo sociólogo José Eduardo Faria em seu livro "Sociologia Jurídica: Direito e Conjuntura" (FARIA, 2010). O autor percebe que, a partir dos anos 80 , os ordenamentos jurídicos se tornaram cada vez mais fragmentados e sem unidade lógica, e uma das tendências apontadas como resultantes desse modelo é a reformulação dos mecanismos processuais, por meio da simplificação de procedimentos, com a redução de formalismos e da burocratização. Nesses termos, é perceptível que a promulgação do novo Código de Processo Civil no Brasil se insere na tendência apontada pelo sociólogo, indicando, uma vez mais, como os institutos jurídicos devem ser analisados dentro de seu contexto, e não de maneira isolada.

4. Mediação e conciliação: conceitos, distinções e modelo do CPC de 2015

O CPC de 2015 define conciliação como o método consensual de resolução de conflitos em que, preferencialmente, não há vínculo anterior entre as partes, conflitos mais simples, portanto (como, por exemplo, acidentes de veículos), em que é permitido ao conciliador propor soluções para o conflito (definição constante nos arts. $1^{\circ}, \S 3^{\circ}$ e $165, \S$ $2^{\circ}$ do CPC de 2015). Já a mediação, é definida como o método consensual de resolução de conflitos mais adequado para aqueles em que há vínculo prévio entre as partes, conflitos, portanto, mais complexos, que visa restabelecer o diálogo entre as partes para que essas, 
por si próprias, cheguem à solução do conflito. Fica subentendido nessa definição que o mediador fica vedado de sugerir soluções para o litígio (definição constante nos arts. $1^{\circ}, \S$ $3^{\circ}$ e $165, \S 3^{\circ}$ do CPC de 2015).

A Resolução n. 125 do CNJ também aborda o tema, apontando a mediação e a conciliação como "instrumentos efetivos de pacificação social, solução e prevenção de litígios”, e a Lei de Mediação (Lei n. 13.140/2015), em seu art. $1^{\circ}$, apresenta especificamente o conceito de mediação, definida como um meio de solução de controvérsias entre particulares, uma técnica exercida por terceiro imparcial sem poder decisório, que, escolhido ou aceito pelas partes, auxilia e estimula a identificar ou desenvolver soluções consensuais para a controvérsia.

Conclui-se, pela análise das referidas fontes, que há uma distinção entre os conceitos de mediação e conciliação, pelo menos no ordenamento jurídico nacional atual. Há quem defenda serem técnicas análogas, porém o próprio CPC apontou distinções entre as duas técnicas (a possibilidade de o terceiro imparcial sugerir soluções, a complexidade dos conflitos, a preferível existência de vínculo anterior entre as partes).

Saindo da análise das fontes puras do Direito, passa-se à Doutrina. Tania Almeida (2008), em seu texto "Mediação e Conciliação: dois paradigmas distintos, duas práticas diversas", discorre sobre essas diferenças. Para a autora, ambos os métodos visam a construção de um consenso sobre certo conflito, mas existiriam diferenças entre os institutos. A conciliação seria marcada por lógica adversarial, visaria o acordo, e os conciliadores ofereceriam soluções para o conflito. Já a mediação visaria a desconstrução do conflito, as partes se juntariam para buscar uma solução, e o mediador atuaria por meio de perguntas e técnicas diversas da proposição de soluções.

Há, porém, quem discorde dessa visão estanque e separada entre os dois métodos consensuais. Erica Barbosa e Silva (2013), em seu texto Conciliação Judicial, se opõe à visão "binária", que distingue e afasta as técnicas de mediação e conciliação. A autora defende que a atuação do terceiro deve se adequar ao tipo de conflito em questão, alegando que nem sempre o mediador precisa ser mais passivo, ou o conciliador mais ativo, por exemplo, a sua atuação deve ser mais dinâmica, passível de mudança e de livre circulação entre as técnicas de acordo com a necessidade e o tipo de litígio.

Apesar da existência de visões distintas sobre o tema, conclui-se que a visão predominante, e inclusive reforçada pelo CPC 2015, é a de que a mediação e a conciliação são métodos consensuais diversos e com aplicação distinta, conforme os já mencionados parágrafos $2^{\circ}$ e $3^{\circ}$ do art. 165 do CPC. 
De forma sintética:

\begin{tabular}{|c|c|}
\hline MEDIAÇÃO & CONCILIAÇÃO \\
\hline $\begin{array}{l}\text { - Conflitos em que, preferencialmente, exista vínculo } \\
\text { entre as partes. } \\
\text { - Mediador não sugere soluções, apenas auxilia as } \\
\text { partes a compreender as questões e interesses em } \\
\text { conflito, para que as partes possam restabelecer a } \\
\text { comunicação e, por si próprias, identificar soluções } \\
\text { consensuais que gerem benefícios mútuos. } \\
\text { - Aplica-se Lei de Mediação (Lei n. 13.140/2015). } \\
\text { - Para conflitos tidos como de "maior } \\
\text { complexidade". }\end{array}$ & $\begin{array}{l}\text { - Conflitos em que, } \\
\text { preferencialmente, não há } \\
\text { vínculo anterior entre as } \\
\text { partes. } \\
\text { - Conciliador pode sugerir } \\
\text { soluções para o litígio. } \\
\text { - Para conflitos vistos } \\
\text { como "mais simples", } \\
\text { ainda que isso possa } \\
\text { variar. }\end{array}$ \\
\hline
\end{tabular}

O modelo do CPC de 2015 funciona, resumidamente, da seguinte forma:

- A parte autora indica na petição inicial seu interesse em realizar ou não uma audiência de mediação ou conciliação;

- A parte contrária manifestará, por meio de petição, seu interesse ou desinteresse na realização da audiência de mediação ou conciliação;

- Caso ambas as partes expressem manifesto desinteresse pela realização da audiência, esta não será realizada, e o réu deverá apresentar contestação;

- Caso ambas as partes desejem a realização da audiência, ou mesmo apenas uma delas, será marcada a audiência de mediação ou de conciliação, ambas as partes serão intimadas por intermédio de um Oficial de Justiça, e deverão comparecer à audiência, sob pena de condenação ao pagamento de multa por ato atentatório à dignidade da Justiça;

- As partes necessariamente devem comparecer à audiência acompanhadas de seus advogados ou defensores públicos;

- Caso haja autocomposição, esta será reduzida a termo e homologada por sentença. Caso não se chegue a solução consensual, passa-se ao oferecimento da contestação por parte do réu;

- As partes têm liberdade para escolher câmara privada de mediação ou conciliação, bem como autonomia para escolher o mediador ou 
conciliador. A liberdade das partes inclui a possibilidade de definir ou alterar regras procedimentais referentes à mediação ou conciliação;

- É possível que as partes constituam representantes para comparecer à audiência em seus lugares, com poderes específicos para transigir e negociar;

- A mediação ou conciliação será regida pelos princípios da independência, da imparcialidade, da autonomia da vontade, da confidencialidade, da oralidade, da informalidade e da decisão informada;

- Os mediadores e conciliadores obedecerão ao dever de confidencialidade e sigilo, serão remunerados de acordo com tabela fixada pelo tribunal obedecendo aos parâmetros estabelecidos pelo CNJ, sendo possível o trabalho voluntário. Os mediadores ou conciliadores que desobedecerem aos seus deveres poderão ser punidos com exclusão do cadastro, após processo administrativo;

- Deverão ser criados centros judiciários de solução consensual de conflitos, onde serão realizadas as audiências, bem como serão criadas câmaras de mediação e conciliação. Também deverão ser criados cadastros estaduais ou federais, em que os mediadores e conciliadores habilitados serão inscritos;

- Os operadores do Direito devem sempre estimular a utilização dos métodos consensuais. Nas ações de família, especialmente, "todos os esforços serão empreendidos para a solução consensual", e o processo pode, inclusive, ser suspenso a requerimento das partes, enquanto durar a mediação, conciliação ou atendimento multidisciplinar;

- Não há vedação à realização de mediações ou conciliações extrajudiciais.

Passa-se à efetiva análise do sistema brasileiro, reunindo as impressões sobre como o modelo de mediação e conciliação previsto pelo CPC 2015 interfere no tratamento dos conflitos como propriedade.

Análise da apropriação dos conflitos no sistema brasileiro trazido pelo CPC de 2015

Há previsões do Novo CPC que podem ser consideradas benéficas no combate à apropriação dos conflitos, e outras que acabam por serem negativas, incorrendo em diversos pontos criticados no artigo Conflicts as Property. De início, serão analisados os aspectos positivos: 


\section{B.1) Da aproximação das partes à resolução de seus conflitos: 0} primeiro ponto positivo a ser constatado é o de que, ao prever os métodos consensuais de resolução de disputas, o CPC acabava promovendo maior participação das partes no processo de solução de conflitos. Essa maior participação ocorre por razões diversas: a principal delas é o fato de os métodos autocompositivos, por definição, permitirem que a solução venha das partes, e não de um terceiro julgador. Além disso, os procedimentos poderão ser realizados em locais mais acessíveis à comunidade (CEJUSCs e JECs, ao invés das formais salas de audiências dos fóruns), e com a utilização de linguagem leiga, ao invés de vocabulário jurídico e técnico, que afastam e confundem as partes. $\mathrm{O}$ autor José Carlos Barbosa Moreira (1999), em seu texto "A linguagem forense", aponta como a não compreensão do que se passa no próprio processo gera desconfiança na parte, que frequentemente acaba suspeitando de ter sido enganada, simplesmente por não ter tido acesso à linguagem técnica utilizada. Todos esses elementos aproximam as partes dos processos de resolução de seus conflitos, combatendo a apropriação destes por terceiros.

B.2) Maior disseminação da Cultura da Pacificação: Kazuo Watanabe (2005) constatou, em seu texto "Cultura da sentença e cultura da pacificação", que vivemos em uma sociedade inserida na cultura da sentença: as pessoas esperam que seus conflitos sejam resolvidos por meio da via judicial, pela imposição de uma decisão proferida por terceiro julgador. $\mathrm{O}$ contrário dessa realidade seria a cultura da pacificação, em que os indivíduos participam ativamente da resolução de suas disputas, aproveitandose de métodos consensuais.

Assim, a previsão do CPC 2015 de ampla utilização de métodos consensuais se insere na política prevista pela já mencionada Resolução n. 125 de 2010 do CNJ, ou seja, auxilia na promoção e divulgação dos métodos consensuais, disseminando-os pela sociedade.

Por óbvio, a superação da cultura da sentença exigirá grande esforço educacional por parte de todas as Universidades, bem como uma manutenção das políticas públicas de incentivo aos métodos consensuais, sendo uma construção a longo e médio prazo. É impossível revolucionar a mentalidade jurídica do país instantaneamente, porém todo pequeno passo na direção de um sistema mais aberto aos métodos consensuais constitui um avanço.

Nesse sentido, o CPC de 2015 contribuiu para a disseminação da cultura da pacificação, visto que inúmeros profissionais e operadores do Direito que nem sequer escutariam falar sobre o tema dos mecanismos ADR passam a conhecer o assunto, através da aplicação básica do Código de Processo Civil. O tema dos métodos consensuais passa a fazer parte da cultura jurídica nacional, um importante passo em direção à disseminação da cultura da pacificação. 


\section{B.3) Criação de alternativas à via judicial e o Sistema Multiportas: um} terceiro aspecto positivo da utilização de métodos consensuais prevista no CPC 2015 é o surgimento de outras possibilidades além do enfrentamento judicial na resolução de conflitos.

Há, entre leigos, a falsa ideia de que a resolução de conflitos deve ocorrer por algum mecanismo específico, aplicado a todo e qualquer tipo de conflito, de maneira indistinta. Essa visão é uma das razões pela qual nosso Poder Judiciário se encontra tão saturado, há número enorme de conflitos sendo resolvidos pela via judicial, incorrendo em problemas como a lentidão, o afastamento das partes de suas próprias disputas, injustiças e afins.

Oposta a esta visão, se encontra aquela que defende o "Sistema Multiportas", um sistema em que é possível acessar a Justiça por meio de inúmeros canais diversificados, gerando, assim, menor lentidão e melhor qualidade de oferecimento da Justiça.

A Min. Nancy Andrighi e a juíza Gláucia Falsarella Foley (2008) já pregavam, desde 2008, a necessidade de um sistema diversificado no combate à cultura que denominavam "excessivamente adversarial", através da implementação de um "sistema de múltiplas portas".

Assim, o Novo CPC promove novas "portas" de acesso à Justiça, sendo possível buscar mecanismos de resolução de conflitos voltados ao consenso, escapandose da lógica judicial e adversarial da cultura da sentença. Os resultados esperados, ainda que o Código seja recente, são a mitigação dos problemas de lentidão e saturação do Judiciário, e o melhor atendimento das demandas da população quanto o acesso à Justiça.

B.4) A profissionalização dos mediadores e conciliadores: o último ponto considerado positivo trazido pelo novo CPC é a profissionalização das funções de mediador e conciliador. O CPC/2015 deixou clara a distinção entre as funções de julgador e mediador/conciliador (ao contrário do Código anterior), e previu capacitação mínima, bem como inscrição em cadastro nacional, possibilidade de realização de concursos públicos para seleção. Enfim, foram criadas regras que organizam a carreira daqueles que atuarão com mediação e conciliação. E não resta dúvida que disponibilizar profissionais melhor qualificados fornece às partes melhores condições de resolver os seus conflitos de maneira consensual.

A importância da capacitação dos mediadores e conciliadores é crucial para o bom desenvolvimento dos métodos consensuais, e diversos autores mencionados durante a pesquisa foram unânimes nessa visão (Kazuo Watanabe, João Pedroso e João Paulo Dias, por exemplo). Porém, restam dúvidas sobre a qualidade da "capacitação mínima” exigida pelo Código, tema que será abordado na sequência. 


\section{Benefícios do Novo CPC:}

- Aproximação das partes à resolução de seus conflitos;

- Disseminação da Cultura da Pacificação e dos métodos ADR;

- Multiplicação de alternativas para resolução de conflitos;

- Profissionalização dos mediadores e conciliadores.

Encerrada a análise dos pontos positivos do Novo CPC, passa-se aos aspectos tidos como preocupantes.

\section{B.5) Dos riscos da capacitação insuficiente dos mediadores e} conciliadores: o primeiro aspecto negativo é, em realidade, continuação da discussão feita acima. Enquanto, anteriormente, se mostrou a relevância da boa capacitação dos mediadores e conciliadores, agora se discutirá os riscos de uma preparação inadequada dos profissionais da área.

$\mathrm{O}$ art. 167 do CPC de 2015 determina que os mediadores e conciliadores deverão preencher requisito de "capacitação mínima", consistente, nos termos do Anexo I da Resolução n. 125 de 29/11/2010, em carga horária mínima de 40 horas/aula no Módulo Teórico e mínimo de 60 horas de estágio supervisionado no Módulo Prático. Ou seja, a título de ilustração: é possível que um mediador ou conciliador se forme com apenas 1 mês de aulas teóricas ( 2 horas de aula por dia útil), e mais as 60 horas de estágio exigidas.

Parece que a formação mínima exigida é curta, em face da enorme responsabilidade envolvendo a função. Deveria ser exigido altíssimo nível de qualificação dos profissionais da área, para que estivessem preparados para lidar com as sutilezas dos mecanismos ADR, com suas diferentes técnicas e ferramentas. É um pouco difícil de se imaginar que em apenas 20 dias com 2 horas/aula por dia os profissionais esgotarão toda a teoria necessária para a capacitação de um mediador ou conciliador, por exemplo.

Assim, questiona-se a "capacitação mínima” exigida pelo art. 167 será suficiente para a boa utilização dos mecanismos consensuais. Parece existir o risco de que os mediadores e conciliadores se formem de maneira incompleta, colocando em risco o funcionamento dos mecanismos ADR previstos pelo CPC. Além disso, a possibilidade de atuação voluntária e a não remuneração adequada dos conciliadores e mediadores acabam afastando os bons profissionais. Há, ainda, regra que proíbe advogados que atuem como mediadores ou conciliadores de advogar nos juízos em que desempenharam essas funções. Tal previsão acaba por afastar os advogados, que não desejam abdicar do exercício da advocacia em certos Juízos para exercer a função de mediadores ou conciliadores, ainda mais quando tais funções nem sequer são bem remuneradas. 


\section{B.6) Da previsão de métodos ADR desacompanhada de mudanças}

culturais na sociedade: o CPC de 2015 trouxe ferramentas autocompositivas completamente desconhecidas para a população, de forma geral, visto que impera a cultura da sentença, descrita por Kazuo Watanabe. Tanto os juízes quanto as partes e advogados estão acostumados com a ideia de que os conflitos devem ser resolvidos por uma sentença proferida por terceiro julgador. Falta a ideia de pacificação, de resolução amigável das disputas através da atuação das próprias partes envolvidas.

Esse traço cultural existe também na cultura jurídica, poucas são as Universidades que ensinam o Direito fora da lógica da litigância. O bom advogado, tanto nas salas dos cursos de Direito como nos filmes e na mídia, é sempre aquele litigador por excelência, que vence os adversários nos Tribunais, nunca aquele que promove o diálogo e soluções amigáveis que beneficiem ambas as partes.

Constatando-se esse forte traço cultural, é preciso questionar qual será a efetividade dos métodos consensuais e amigáveis previstos pelo CPC de 2015 sem que exista uma mudança da cultura paralela à utilização dos mecanismos ADR. De que adianta as partes comparecerem à audiência de mediação ou conciliação se estiverem imbuídas de espírito adversarial e litigante? É provável que as tentativas de resolução consensuais falhem, por ausência da própria compreensão da lógica consensual. É necessário que as partes estejam abertas a estes mecanismos, e para que isso ocorra, é preciso que sejam inseridas na cultura da pacificação, via políticas públicas de educação sobre os métodos consensuais e informação sobre seus direitos.

Neste sentido, as Universidades ocupam um papel importante, devendo formar profissionais do Direito que conheçam a lógica da pacificação.

Nils Christie exalta o papel das Universidades em Conflicts as Property, propondo uma visão questionadora do Direito, e não um ensino doutrinário e engessado, a serviço do status quo. A Faculdade de Direito da Universidade de São Paulo, a título de exemplo, embora apresente iniciativas pontuais, como o grupo de estudos NEMESC (Núcleo de Estudos de Mecanismos de Solução de Conflitos) ou como uma ou outra disciplina optativa ("Disciplina: DPC0433 - Mediação e Conciliação Judiciais e Extrajudiciais", por exemplo), não possui em seu currículo regular obrigatório o estudo intenso da utilização de métodos autocompositivos. Ou seja, a maioria dos alunos que passam pela graduação da Faculdade de Direito da USP talvez nunca estudem de forma específica, pelo menos não durante os cinco anos da graduação, o tema dos métodos consensuais, demonstrando o quanto os métodos ADR ainda são vistos como "alternativos", como uma possibilidade à qual os alunos podem ou não recorrer, e não como um requisito para que o profissional do Direito atue no mercado.

Retornando ao CPC de 2015, reitera-se a necessidade de que os mecanismos ADR previstos sejam acompanhados por uma verdadeira transformação cultural, tanto da 
população leiga quanto dos operadores do Direito, para que se possa atingir uma efetiva utilização dos métodos consensuais de resolução de conflitos.

Do ponto de vista das críticas feitas pelo Nils Christie, percebe-se a necessidade de que as portas do universo jurídico sejam abertas aos leigos, para que a resolução dos conflitos parta, cada vez mais, da sociedade para o ordenamento jurídico, e não de maneira inversa. Para que isso seja possível, é indispensável que a própria população tenha acesso ao mundo dos métodos consensuais de resolução de conflitos.

B.7) Do risco das mediações/conciliações "pro forma": o terceiro aspecto a ser analisado é a questão da efetividade das audiências de mediação e conciliação. Diversos aspectos (cultura da sentença, rapidez das mediações e conciliações, participação de empresas desinteressadas em dialogar, partes que comparecem aos procedimentos amigáveis de maneira compulsória) acabam por minimizar as chances da realização de uma verdadeira sessão de mediação ou conciliação, e aumentam, por sua vez, o número de audiências "simuladas", pro forma, em que as partes comparecem à audiência apenas para dizer que não há acordo, e simplesmente para se livrar deste requisito formal, para que possam passar aos próximos estágios do processo, sem que haja tentativa efetiva de resolução do conflito pelas vias consensuais.

Há que se convencer a sociedade das inúmeras vantagens dos métodos autocompositivos em comparação à via jurisdicional, para potencializar as boas realizações das audiências de mediação e conciliação. Os autores Garth e Cappelletti (1978), no artigo Access to Justice: The Newest Wave in the Worldwide Movement to Make Rights Effective, apontam que os mecanismos ADR trazem diversas vantagens (economia de tempo e dinheiro, melhor implementação das decisões, preservação de relações comerciais), devendo ser instituídas políticas públicas de divulgação e promoção desses benefícios, para que os principais envolvidos em litígios no país percebam as possibilidades dessa nova realidade e alterem suas práticas jurídicas e sua postura quanto aos métodos ADR.

Críticas ao modelo do CPC de 2015:

- Modelo prevê mecanismos ADR sem que a sociedade esteja inserida na cultura da pacificação, necessidade de mudanças culturais;

- Capacitação mínima dos mediadores e conciliadores poderia ser ampliada;

- Advogados acabam afastados da função de mediadores e conciliadores;

- Possibilidade de proliferação das mediações e conciliações pro forma, simulações ao invés de efetivas tentativas consensuais de solucionar conflitos. 


\section{Conclusão da pesquisa}

Essa pesquisa procurou analisar de maneira crítica a utilização dos mecanismos de mediação e conciliação no Código de Processo de 2015, com base nas ideias de Nils Christie em Conflicts as Property. Foram constatados alguns pontos positivos trazidos pelo Novo $\mathrm{CPC}$, bem como foram tecidas algumas críticas. De maneira sintética, pode-se dizer que o Brasil, inserido em um movimento supranacional de adoção dos mecanismos ADR e de crise da Justiça nas nações ocidentais modernas, optou pela promoção da cultura da pacificação e dos métodos consensuais, aproximando as partes das tentativas de resolução de seus conflitos, em uma tentativa de combater alguns dos problemas que marcam o Judiciário brasileiro. Por outro lado, o CPC de 2015 trouxe mecanismos desconhecidos da população, e distanciados da cultura da sentença predominante, sem que haja uma ampla tentativa governamental de informar e educar a sociedade quanto às mudanças instituídas. Qual a conclusão que se tira desta pesquisa?

Vale relembrar que Nils Christie criticava um modelo jurídico em que as partes eram alienadas da resolução de seus conflitos, em que os operadores do Direito tomavam as disputas para si, afastando as partes e a comunidade, e utilizando-se de diversas ferramentas para afastar os leigos dos processos, além de apontar um descompasso entre o ensino jurídico e as reais necessidades da sociedade.

Resta claro que o modelo ocidental de tratamento de temas como a resolução de conflitos e a aplicação da Justiça, criticado por Christie, está em crise. Diversos países de realidades distintas estão buscando mecanismos alternativos de resolução de conflitos, e o CPC de 2015, com sua ampla previsão de utilização de mecanismos ADR, deve ser entendido dentro de um movimento supranacional, que transcende as fronteiras brasileiras.

O Brasil é um país de litigiosidade exacerbada, com um Poder Judiciário saturado, que forma mais operadores do Direito do que a real necessidade da sociedade, e que é marcado por uma lógica de litigância nos processos de resolução de conflitos. Além disso, o cenário jurídico é dominado por formalismos e estruturas que acabam por afastar as partes da resolução de seus conflitos.

Frente a este cenário, percebe-se que o Novo CPC traz algum grau de melhoria: ao instituir ampla utilização dos mecanismos ADR, tenta combater a alienação das partes dos processos de resolução de suas disputas, envolvendo-as, fazendo com que participem da solução de seus problemas. Além disso, os mecanismos consensuais prezam por certa informalidade, e certamente serão úteis na tentativa de vencer o formalismo da cultura jurídica nacional.

Porém, o CPC não opera milagres: uma simples mudança legislativa não basta para revolucionar toda a cultura da sentença e toda a litigiosidade que compõem a realidade forense brasileira. Além disso, ainda é cedo para constatar como os mecanismos 
de mediação e conciliação previstos no CPC de 2015 serão utilizados no dia a dia. É possível que as suas utilizações sejam desvirtuadas (talvez pela desinformação das partes, talvez pela cultura jurídica em que os operadores do Direito estão envolvidos), e que muitos dos seus benefícios se percam pela má utilização dos métodos previstos.

Por essa razão, ressalta-se a responsabilidade das Universidades, que possuem o dever de construir um ensino jurídico adequado às reais necessidades da sociedade, formando profissionais questionadores, que não sejam parte do problema, e sim que auxiliem na construção de soluções, promovendo a cultura da pacificação, da restauração e da inclusão da sociedade leiga nos processos de resolução de conflitos.

São Paulo, abril de 2018.

\section{Referências}

ALMEIDA, Tania. Mediação e conciliação: dois paradigmas distintos, duas práticas diversas. In: CASELLA, Paulo Borba; SOUZA, Luciane Moessa. (Coord.). Mediação de conflitos: novos paradigma de acesso à Justiça. Belo Horizonte: Fórum, 2008.

ANDRIGHI, Nancy; FOLEY, Gláucia Falsarella. Sistema multiportas: o judiciário e o consenso. Folha de S. Paulo, São Paulo, 24 jun. 2008.

CHRISTIE, Nils. Conflicts as property. The British Journal of Criminology, Oxford, v. 17, n. 1, p. 1-15, Jan. 1977.

DIAS, João Paulo; PEDROSO, João. As crises e as reformas da administração da justiça. Lisboa: OBSERVARE. Universidade Autónoma de Lisboa, 2004. p. 184-185. (OBSERVARE - JANUS 2004 - O mundo e a justiça).

FARIA, José Eduardo. A sociologia jurídica: direito e conjuntura. 2. ed. São Paulo: Saraiva, 2010. (Série G Vlaw).

GALANTER, Marc. Direito em abundância: a actividade legislativa no Atlântico Norte. Revista Crítica de Ciências Sociais, Coimbra, n. 36, p. 103-145, fev. 1993.

GARTH, Bryant G.; CAPPELLETTI, Mauro. Access to justice: the newest wave in the worldwide movement to make rights effective. Buffalo Law Review, Buffalo, New York, v. 27, n. 2, p. 181-292, 1978. Disponível em: <http://www.repository.law.indiana.edu/facpub/1142>.

MINISTÉRIO DA FAZENDA. Secretaria de Política econômica. Reformas microeconômicas e crescimento a longo prazo. Brasília, DF: [s.n.], 2004. p. 80-81.

MOREIRA, José Carlos Barbosa. A linguagem forense. Carta Mensal, Rio de Janeiro, v. 45, n. 530, p. 11-20, maio 1999. Disponível em: <http://www.ebah.com.br/content/ABAAAAhp0AI/alinguagem-forense>. Acesso em: 14 ago. 2017. 
PUCCI, Rafael Diniz. Governança ambiental e sistema financeiro internacional: significantes e significados de complexa comunicação na agenda contemporânea. Revista da Faculdade de Direito da Universidade de São Paulo, São Paulo, v. 110, p. 641-673, jan./dez. 2015.

SILVA, Érica Barbosa e. Conciliação judicial. Brasília, DF: Gazeta Jurídica, 2013. p. 173. (Coleção MASC - Meios alternativos de solução de conflitos; v. 3).

WATANABE, Kazuo. Cultura da sentença e cultura da pacificação. In: SALETTI, Achille et al. Estudos em homenagem à professora Ada Pellegrini Grinover. São Paulo: DPJ, 2005.

ZEHR, Howard. The little book of restorative justice. Pennsylvania: Good Books, 2002. 